\begin{abstract}
Iranica
Abstracta Iranica Revue bibliographique pour le domaine irano-aryen

Volume 34-35-36 | 2017

Comptes rendus des publications de 2011-2013
\end{abstract}

\title{
John W. Watt, Rhetoric and Philosophy from Greek into Syriac
}

\section{Florence Jullien}

\section{(2) OpenEdition}

\section{Journals}

\section{Édition électronique}

URL : http://journals.openedition.org/abstractairanica/41349

DOI : 10.4000/abstractairanica.41349

ISSN : 1961-960X

Éditeur :

CNRS (UMR 7528 Mondes iraniens et indiens), Éditions de l'IFRI

Référence électronique

Florence Jullien, « John W. Watt, Rhetoric and Philosophy from Greek into Syriac », Abstracta Iranica [En ligne], Volume 34-35-36 | 2017, document 1, mis en ligne le 15 juillet 2016, consulté le 02 octobre 2020. URL : http://journals.openedition.org/abstractairanica/41349; DOI : https://doi.org/10.4000/ abstractairanica.41349

Ce document a été généré automatiquement le 2 octobre 2020.

Tous droits réservés 


\title{
John W. Watt, Rhetoric and Philosophy from Greek into Syriac
}

\author{
Florence Jullien
}

\section{RÉFÉRENCE}

John W. Watt. Rhetoric and Philosophy from Greek into Syriac. Farnham, Ashgate, 2010, 330 p. (Variorum Collected Studies Series CS 960)

1 Ce volume est le fruit des importantes recherches menées par l'A. sur le thème de la transmission et du développement de la culture grecque dans les milieux syriaques savants de Syrie et de Mésopotamie entre $\mathrm{VI}^{\mathrm{e}}$ et $\mathrm{IX}^{\mathrm{e}} \mathrm{s}$., plus spécifiquement dans les domaines de la rhétorique et de la philosophie. De Serge de Rešayna, premier auteur syriaque à rédiger un ouvrage sur Aristote, à Abu Bišr Matta ibn Yunus, élève à l'école de Dayr Qunna en Babylonie centrale puis enseignant à Bagdad, maître du philosophe al-Fārābī et du chrétien syro-orthodoxe Yahya ibn 'Adi qui s'illustra par ses traductions d'Aristote du syriaque en arabe, les articles ainsi réunis retracent la réception de la littérature philosophique grecque et son appropriation, en particulier via les modes d'apprentissage, la paideia et les cursus scholastiques des écoles monastiques syriaques. Celles-ci ont par là-même constitué un maillon de transmission fondamental vers le Proche-Orient médiéval et la civilisation islamique. 


\section{AUTEURS}

\section{FLORENCE JULLIEN}

CNRS, Mondes iranien et indien, Paris 